\title{
Assessing laptop use in higher education classrooms: The Laptop Effectiveness Scale (LES)
}

\author{
Sharon Lauricella and Robin Kay \\ University of Ontario Institute of Technology
}

\begin{abstract}
Considerable research has been conducted examining the use of laptops in higher education, however, a reliable and valid scale to assess in-class use of laptops has yet to be developed. The purpose of the following study was to develop and evaluate the Laptop Effectiveness Scale (LES). The scale consisted of four constructs: academic use and three areas of non-academic use (communication, watching movies, playing games). Tested on 177 higher education students, the data generated using the LES showed acceptable internal reliability, construct validity, content and convergent validity. Feedback from students suggested that both academic and non-academic constructs assessed by the LES could be expanded to incorporate a wider range of laptop related behaviour.
\end{abstract}

\section{Overview}

There is extensive debate about the efficacy of laptop computers in the classroom. Several studies have identified benefits such as keeping students on task and engaged (Hyden, 2005), or following lectures via PowerPoint or multimedia (Debevec, Shih \& Kashyap, 2006). However, other research indicates that using laptops in class can be a disadvantage (Fried, 2008). For example, in lecture based classes, students have been reported using laptops for social activities such as surfing the web and sending emails (Barkhuus, 2005; Barak, Lipson \& Lerman, 2006). To date, no systematic measure of inclass laptop behaviour has been designed for higher education. The purpose of this paper is to introduce and evaluate a scale that can be used to assess the in-class effectiveness of laptops.

\section{Laptop use in higher education}

A number of themes have emerged regarding the use of laptops in higher education including general use, communication, student attitudes toward learning, student achievement, and distractions. Each of these will be discussed in turn.

\section{General use}

Researchers have examined how students use laptops for learning. For example, Demb, Erickson and Hawkins-Wilding (2004) found that $16 \%$ of overall laptop use involved typing papers and notes. Arend's (2004) work showed that out of class work such as writing papers, using software programs, searching the Internet, and completing group projects constituted the bulk of laptop use. McVay, Snyder and Graetz (2005) added that students reported using their laptops an average of five hours per day, with $36 \%$ of that time being spent on academic activities. 


\section{Communication}

Students report that using a laptop to communicate with faculty via email is generally gratifying (Mitra \& Steffensmeier, 2000), and that with email, they communicate with faculty more often and more freely (Arend, 2004). Traditional office hours are being replaced with email communication (Dickson \& Segars, 1999; Reynolds, 2003), as students can ask brief questions of faculty without having to meet in person. This asynchronous communication allows for greater flexibility for students and faculty, and also provides faculty with an electronic record of student advising and counselling (Partee, 1996). Brown and Pettito (2003) suggest that email is becoming ubiquitous in that, "a majority of academic communities are presuming that students and faculty communicate via email" (p. 26).

Email communication in education is not limited to faculty-student interactions. Demb, et al. (2004) suggest that laptops offer students the opportunity to engage in peer-to-peer communication via email, chat rooms, bulletin boards and instant messaging. This kind of mobile communication, including multimedia messaging, web access, email and voice/text messaging, provides short learning activities that are attractive to students and foster collaboration (Shih \& Mills, 2007). Gay, Stefanone, Grace-Martin and Hembrooke (2001) suggest that within a collaborative learning environment, students working in groups recognise and use social communication for the exchange of information, and that wireless connections increase the ability for students to collaborate whenever and wherever they want.

Although email and instant messaging technologies suggest increased communication among faculty and students, use of these communication tools is potentially detrimental in the classroom. Grace-Martin and Gay (2001) found that recreational email and instant messaging are among the primary uses of wireless laptops by students, while Crook \& Barrowcliff (2001) suggest that recreational use of email and instant messaging in class can be distracting to students. Some attempts at quantifying the time spent on non-academic communication and social distraction have been made, such as Barak, et al. (2006), who found that $12 \%$ of students used their laptops for non-learning purposes such as web surfing or social emailing. Crook \& Barrowcliff (2001) also found evidence of recreational laptop activity, arguing that the selfreported work:play ratio of in student interviews was 30\%:70\%.

\section{Student attitudes toward learning}

Jones (2002) found that a majority of college students own computers and wireless devices and believe that Internet use has enhanced their learning experience. Similarly, alumni who participated in an undergraduate laptop program agreed that portable computers were beneficial in their college careers (Finn \& Inman, 2004). Mitra and Steffensmeier (2000) found that students who used laptops preferred taking classes where they could use the computer. Despite the affinity for using the computer, student satisfaction is higher when students report using the laptops for academic purposes (McVay, Snyder \& Graetz, 2005).

A number of studies have reported that students believe that laptops make learning "easier" (Barak, et al., 2006; Mitra \& Steffensmeier, 2000; Hyden, 2006; Weaver \& Nilson, 2005). This may be an extension of the notion that modern students have grown up with technology, and the progression to having the "convenience of a personally configured computer [that] students naturally use it as a life tool" (Brown \& 
Pettito, 2003, p. 27). Caudill (2007) suggests that by carrying a personalised device, students can quickly and easily access the resources they need.

\section{Student achievement}

Zucker (2004) argues that increasing student achievement is the most important goal for adopting 1:1 computing, and that studies focusing on student learning deserve a high priority. Results from studies measuring the efficacy of laptops on student achievement, though, are mixed. Demb, et al. (2004) found that for about two-thirds of students, the laptop computer made a significant difference in study habits, with students reporting that the laptops helped with classroom assignments, email, communication and research. Similarly, Siegle \& Foster's (2001) observations indicated that students benefited from using PowerPoint presentations and reviewing course material via the laptop. On the other hand, Wurst, Smarkola and Gaffney (2008) observed that students felt multitasking was a distraction from academics while in class. Fried (2008) also found that students who used laptops in class spent considerable time multitasking and that the level of laptop use was negatively related to overall course performance.

\section{Distractions}

The potential for the laptop to distract students may be the most significant drawback to its use. Hembrooke and Gay (2003) set out to systematically investigate students multitasking behaviour, as they found evidence that students were "engaged in computing activities that were often unrelated to the immediate class lecture and tasks" (p. 48). Barkhuus (2005) also observed that students with laptops in class were surfing the internet, emailing or writing assignments during a lecture. The tendency to engage in multitasking is of particular interest because paying attention "plays a critical role in issues of motivation, engagement and learning across educational settings" (Rapp, 2006, p. 604).

It has been argued, though, that students raised in the era of multitasking can successfully balance Internet use and classroom participation (Young, 2006). Distraction in the lecture hall is "nothing new", as doodling, note passing, or completing other assignments, function as simply low-tech distraction (Hembrooke \& Gay, 2003, p. 47), and games, email or messaging substitutes for traditional doodling (Bhave, 2002). In contrast to researchers advocating the use of attention-aware systems which direct users' attention to the task at hand, Hembroke and Gay (2003) suggest that multitasking and resulting distraction can be mitigated with self discipline, and that students who are able to take brief breaks and return to on-task activities will not suffer the same detriments as students who engage in prolonged web surfing (p. 59).

\section{Methodological issues}

There are at least four noteworthy issues with respect to methods used to assess and evaluate the use of laptops in higher education. First, the predominant method of data collection is the case study (Weaver, 2005; Weaver \& Nilson, 2005; Hyden, 2005; Birrenkott, Birtrand \& Bolt, 2005; Brown, 2005; Granberg \& Witte, 2005; Ohland \& Stephan, 2005; Pargas \& Weaver, 2005; Stephens, 2005; McVay, Snyder \& Graetz, 2005). While this approach offers guidance and advice on best practices for using laptops, the reliability and validity of the data have yet to be confirmed for the general population. 
Second, some studies have employed quasi-experimental methods to assess the impact of laptops on student achievement (Hembrooke \& Gay, 2003; Siegle \& Foster (2001); Trimmel \& Bachmann, 2004). These studies do not offer data on how laptops are actually used in higher education classrooms.

Third, a number of studies involve students who were not provided equal access to technology. Motiwalla's (2007) paper on using handheld devices in class is innovative, yet it is not truly indicative of the benefits and drawbacks of mobile learning because many of the students in the sample did not have devices equipped with the technology essential to participate in the study. Similarly, in with Barkhuus's (2005) study, not all students had a laptop.

Finally, the vast majority of studies offered no reliability or validity estimates for the measures used to assess laptop behaviour (Barak, et al., 2006; Debevec, Shish \& Kashyap, 2006; Kitsantas \& Chow, 2008; Shih \& Mills, 2007). While the data from these studies offers useful suggestions regarding laptop use, we argue that a more systematic approach to measuring laptop use inside the classroom is also needed.

\section{Method}

\section{Context}

The study took place at University of Ontario Institute of Technology, a small university (just under 5000 students) located in a large metropolitan area. Every student in the university was issued a laptop computer and the campus was completely wireless so students had $24 / 7$ access to the Internet. Students participated in weekly lectures, but had access to a variety of course materials distributed through an online learning management system. While the majority of class time was spent lecturing, a number of laptop based activities were used, including online attitude and opinion surveys, online quizzes, posting comments in discussion boards, online research, in-class creation of charts and concept maps, and viewing online videos.

\section{Sample}

The sample consisted of 177 higher education students ( 89 males, 88 females), in their first $(n=74)$, second $(n=59)$, third $(n=30)$ or fourth year $(n=13)$ of study. Seventy-five percent $(n=132)$ of the students were born in Canada and $86 \%(n=153)$ reported that English was their first language. Students were enrolled in social science $(n=108)$, business $(n=43)$, engineering $(n=11)$, science $(n=12)$ or health science $(n=3)$. Twentyfour of the 177 students did not have English as their first language. The average grade of first year students before they entered UOIT was 78.9 percent (S.D. $=6.3$, range 65 to 90). The average grade for second to fourth students was 74.6 percent (S.D. $=7.8$, range 59 to 90$)$. Almost $85 \%(\mathrm{n}=149)$ of the students reported that they were either proficient $(n=94)$ or very proficient $(n=55)$ in using computers. Average daily use of laptop computers reported by students was 8.8 hours (S.D. $=4.4$, range 2 to 16). All students leased a laptop that was imaged specifically to their selected program and had wireless access to the web throughout campus.

\section{Procedure}

At the conclusion of the final class meeting in December 2007, students were invited to participate in an anonymous, online survey by following a link provided by the 
instructor. Participation was voluntary and participants could withdraw from the study at any time. The instructor was unable to determine who chose to participate and data was not accessed until all marks for the courses were submitted. It took approximately 10-15 minutes for students to complete the survey. The total number of students in both courses was 521, resulting in an approximate coverage rate of $34 \%$.

\section{Data sources}

\section{Descriptive variables}

All students were asked their age, gender, year of study, and average grade at UOIT. They were also asked how much time they spent in total on non-academic activities during class and whether, overall, they felt that laptops helped them academically (see Lauricella \& Kay, 2009).

\section{LES survey}

The LES scale consisted of four constructs (see Lauricella \& Kay, 2009 for a copy of the scale). These constructs were created based on the literature review which suggested that the most salient variables were those that focussed on academic and non-academic use. The first construct consisted of 4 items and assessed the academic use of laptops during class (Academic - class use). The second construct assessed non-academic use of laptops during class for the purpose of communicating to others (Communication). The third construct assessed non-academic use of laptops during class for the purpose of watching movies (Watching movies). The fourth construct assessed non-academic use of laptops during class for the purpose of playing games (Playing games). Descriptive statistics for the LES are presented in Table 1.

Table 1: Description of Laptop Effectiveness Scale (LES)

\begin{tabular}{|l|l|c|c|c|}
\hline \multicolumn{2}{|c|}{ Scale } & $\begin{array}{c}\text { Number } \\
\text { of items }\end{array}$ & $\begin{array}{c}\text { Possible } \\
\text { range }\end{array}$ & $\begin{array}{c}\text { Internal } \\
\text { reliability }\end{array}$ \\
\hline Academic use & 4 & 0 to 16 & $r=0.87$ \\
\hline \multirow{2}{*}{ Non-academic use } & Communication & 4 & 0 to 16 & $r=0.85$ \\
\cline { 2 - 5 } & Watching movies & 2 & 0 to 8 & $r=0.85$ \\
\cline { 2 - 5 } & Playing games & 2 & 0 to 8 & $r=0.70$ \\
\hline
\end{tabular}

Student comments

Students were asked two open ended questions about (a) how laptops were helpful during class time and (b) how laptops were not helpful during class time. Twohundred and thirty four comments were made about the laptop being helpful and 108 comments were offered about the laptop not being helpful. These open ended items were categorised and rated independently by two raters. Comments where categories were not exactly the same were shared and reviewed a second time by each rater. Using this approach, an inter-rater reliability of $99 \%$ was attained for categories.

\section{Data analysis}

A series of analyses were run to assess the reliability and validity of the LES. These included:

1. internal reliability estimates for the LES constructs (reliability);

2. a principal component factor analysis for the LES (construct validity);

3. correlations among constructs within the LES scale (construct validity); 
4. correlation between LES and descriptive variables - average grade, time spent on non-academic activities, whether laptops helped academics (convergent validity);

5. frequency of laptop behaviours assessed by the LES constructs (content validity);

6. student comments (content validity).

\section{Results}

\section{Internal reliability}

The internal reliability estimates for the LES constructs based on Cronbach's alpha were 0.87 (Academic use), 0.85 (Non-academic: Communication), 0.85 (Non-academic: Watching movies), and 0.70 (Non-academic: Playing games) - see Table 1. These moderate to high values are considered acceptable levels for measures in the social sciences (Kline, 1999; Nunnally, 1978).

\section{Construct validity}

Principal component analysis

To date, reliable and valid scales assessing the impact of laptops during class have not been developed, therefore the use of a confirmatory factor analysis is not warranted. Instead, a principal components analysis was done to explore whether the four learning object constructs (academic use, non academic -communication, watching movies, playing games) in the LES formed four distinct factors. Since all communalities were above 0.4 (Stevens, 1992), the principal component analysis was deemed an appropriate exploratory method (Guadagnoli \& Velicer, 1988). The results from the varimax rotation (using Kaiser normalisation) are presented because they simplify the interpretation of the data (Field, 2005). The Kaiser-Meyer-Olkin measure of sampling adequacy $(0.643)$ and Bartlett's test of sphericity $(p<.001)$ indicated that the sample size was acceptable.

The principal components analysis produced four factors (academic use, non-academic - communication, watching movies, playing games) which corresponded well with the proposed laptop effectiveness constructs (Table 2). There was no overlap among constructs with respect to loadings.

Correlations among LES constructs

The correlations among the LES constructs were modest but significant ranging from 0.15 to 0.41 (Table 3). Academic use of laptops during class was negatively correlated with all three non-academic use constructs (communication, moves, and games). The three non-academic constructs were significantly and positively correlated with each other. Shared variances, ranging from $7 \%$ to $17 \%$ were small enough to support the assumption that each construct measured was distinct.

\section{Convergent validity}

Academic use

The correlation between academic use of laptops in class and average grade was not significant $(r=0.14, n$.s.). However, academic use was significantly and negatively correlated with total time spent on non-academic activities $(r=-0.22, p<.01$ in course where survey was taken, $r=-0.30, p<.01$ other courses). Finally, academic use was significantly and positively correlated with student perceptions of whether laptops helped them academically $(r=0.39, p<.01)$. 
Table 2: Varimax rotated factor loadings on Laptop Effectiveness Scale (LES)

\begin{tabular}{|c|c|c|c|c|c|c|}
\hline \multicolumn{3}{|r|}{ In-class activities } & $\begin{array}{c}\text { Factor } \\
1\end{array}$ & $\begin{array}{c}\text { Factor } \\
2\end{array}$ & $\begin{array}{c}\text { Factor } \\
3\end{array}$ & $\begin{array}{c}\text { Factor } \\
4\end{array}$ \\
\hline \multirow{4}{*}{$\begin{array}{l}\text { Academic - } \\
\text { in class use }\end{array}$} & \multicolumn{2}{|c|}{ Take notes (other classes) } & .875 & & & \\
\hline & \multicolumn{2}{|c|}{ Use laptop for academic activities (other classes) } & .862 & & & \\
\hline & \multicolumn{2}{|c|}{ Take notes (this class) } & .860 & & & \\
\hline & \multicolumn{2}{|c|}{ Use laptop for academic activities (this classes) } & .796 & & & \\
\hline \multirow{8}{*}{$\begin{array}{l}\text { Non- } \\
\text { academic }\end{array}$} & \multirow{4}{*}{$\begin{array}{l}\text { Commun- } \\
\text { ication }\end{array}$} & Use email for non-academic (other class) & & .875 & & \\
\hline & & $\begin{array}{l}\text { Instant messaging for non-academic } \\
\text { (this class) }\end{array}$ & & .812 & & \\
\hline & & $\begin{array}{l}\text { Instant messaging for non-academic } \\
\text { (other class) }\end{array}$ & & .807 & & \\
\hline & & Use email for non-academic (this class) & & .807 & & \\
\hline & \multirow{2}{*}{$\begin{array}{l}\text { Watching } \\
\text { movies }\end{array}$} & Watch movies (this class) & & & .896 & \\
\hline & & Watch movies (other class) & & & .896 & \\
\hline & \multirow{2}{*}{$\begin{array}{l}\text { Playing } \\
\text { games }\end{array}$} & Play games (other class) & & & & .904 \\
\hline & & Play games (this class) & & & & .749 \\
\hline
\end{tabular}

\begin{tabular}{|c|c|c|c|}
\hline Factor & Eigenvalue & \% of variance & Cumulative $\%$ \\
\hline 1 & 3.79 & 31.6 & 31.6 \\
\hline 2 & 2.79 & 23.3 & 54.9 \\
\hline 3 & 1.42 & 11.8 & 66.7 \\
\hline 4 & 1.14 & 9.5 & 76.3 \\
\hline
\end{tabular}

Table 3: Correlations among Laptop Effectiveness Scale constructs

\begin{tabular}{|c|c|c|c|c|c|}
\hline & \multirow[b]{2}{*}{ Scale } & \multicolumn{4}{|c|}{ Non-academic } \\
\hline & & $\begin{array}{l}\text { Academic } \\
\text { use }\end{array}$ & $\begin{array}{l}\text { Commun- } \\
\text { ication }\end{array}$ & $\begin{array}{c}\text { Watching } \\
\text { movies }\end{array}$ & $\begin{array}{c}\text { Playing } \\
\text { games }\end{array}$ \\
\hline \multicolumn{2}{|l|}{ Academic use } & 1.00 & -0.15 & $-0.17^{*}$ & $-0.21^{*}$ \\
\hline \multirow[t]{3}{*}{ Non-academic } & Communication & & 1.00 & $-0.41^{\star *}$ & $-0.26^{\star *}$ \\
\hline & Watching movies & & & 1.00 & $-0.26^{* *}$ \\
\hline & Playing games & & & & 1.00 \\
\hline
\end{tabular}

\section{Non-academic communication}

The correlation between non-academic communication use of laptops and average grade was significant and negative $(r=-0.33, p<.01)$. Non-academic communication use was significantly and positively correlated with total time spent on non-academic activities $(r=-0.54, p<.01$ in the course where survey was taken, $r=-0.56, p<.01$ other courses). Finally, the correlation between non-academic communication use and student perceptions of whether laptops helped them academically was not significant $(r=0.10$, n.s. $)$.

Watching movies

The correlation between non-academic movie use of laptops and average grade was not significant $(r=-0.13$, n.s. $)$. Non-academic movie use was significantly and positively correlated with total time spent on non-academic activities $(r=-0.32, p<.01$ in course where survey was taken, $r=-0.37, p<.01$ other courses). Finally, non academic movie use was significantly and negatively correlated with student perceptions of whether laptops helped them academically $(r=-0.18, p<.05)$. 


\section{Playing games}

The correlation between non-academic games use of laptops and average grade was significant and negative $(r=-0.27, p<.01)$. Non-academic games use was significantly and positively correlated with total time spent on non-academic activities $(r=-0.30, p$ $<.01$ in course where survey was taken, $r=-0.45, p<.01$ other courses). Finally, the correlation between non-academic communication use and student perceptions of whether laptops helped them academically was not significant $(r=0.04, n$.s. $)$.

\section{Content validity}

Frequency of laptops behaviour observed

The frequency distribution of behaviours assessed by the LES scale is presented in Table 4. Students estimated the percentage of class time in which they engaged in academic and non-academic activities. Most students spent over $50 \%$ of class time either taking notes $(74 \%)$ or engaging in academic activities $(68 \%)$. Over $70 \%$ of students spent up to $50 \%$ of class time sending non-academic email messages. Fifty-six percent of students exchanged instant messages up to $50 \%$ of the time during class, thirty-one percent of students spent over $50 \%$ of class time instant messaging. Just over one third of students played games up to $50 \%$ of the time in-class. Finally, just $10 \%$ of students watched movies up to $50 \%$ of in-class time.

Table 4: Frequency of in-class laptop behaviours assessed by the LES Scale $(n=177)$

\begin{tabular}{|l|l|c|c|c|c|c|}
\cline { 3 - 7 } \multicolumn{2}{c}{ In-class activities } & \multicolumn{5}{c|}{ Percentage of class time } \\
\cline { 2 - 7 } & & $0 \%$ & $1-25 \%$ & $26-50 \%$ & $51-75 \%$ & $76-100 \%$ \\
\hline \multirow{3}{*}{ Academic } & Take notes & $2 \%$ & $8 \%$ & $15 \%$ & $34 \%$ & $40 \%$ \\
\cline { 2 - 7 } & Academic activities & $3 \%$ & $9 \%$ & $20 \%$ & $31 \%$ & $37 \%$ \\
\hline \multirow{3}{*}{ Non-academic } & Use email & $12 \%$ & $41 \%$ & $31 \%$ & $10 \%$ & $5 \%$ \\
\cline { 2 - 7 } & Instant messaging & $8 \%$ & $32 \%$ & $24 \%$ & $17 \%$ & $14 \%$ \\
\cline { 2 - 7 } & Watching movies & $89 \%$ & $6 \%$ & $4 \%$ & $0 \%$ & $1 \%$ \\
\cline { 2 - 7 } & Playing games & $63 \%$ & $24 \%$ & $11 \%$ & $1 \%$ & $1 \%$ \\
\hline
\end{tabular}

Student comments on laptops being helpful

Items in the LES for assessing academic use of laptops included note taking and using the laptop for other academic purposes. Forty-seven percent $(n=110)$ of all student comments focused on some aspect of notes including taking notes, sharing notes, or using lecture notes. Twenty-four percent $(n=56)$ of the student comments referred to an "academic use" of laptops during class (activities, communicating to other students, using course resources). It is worth noting that $28 \%(n=65)$ of the student comments targeted general aspects of learning that were assisted by the presence of a laptop: being more organised, increasing efficiency, and improving focus or attention in class. Finally, a small subset of students with special needs $(n=3)$ commented that the laptop was helpful in supporting areas of weakness.

Student comments on laptops not being helpful

The LES identified communication, watching movies, and playing games as key distractions when using a laptop during class. Comments from students confirmed that these three behaviours were indeed counter productive. Specifically, students reported communication $(22 \%, \mathrm{n}=24$ comments), playing games $(19 \%, \mathrm{n}=21$ comments), and to a lesser extent watching movies $(10 \%, \mathrm{n}=11)$ as being unhelpful. In addition, a large group of students $(27 \%, \mathrm{n}=29)$ noted that laptops were generally distracting during class. Seven percent of the students added that laptops limited their 
focus $(7 \%, \mathrm{n}=8)$. Finally, surfing the web was acknowledged as being unhelpful by 8 students $(7 \%)$.

\section{Discussion}

The purpose of this study was to develop and evaluate a scale used to assess classroom use of laptops. Careful attention was paid to addressing methodological concerns noted in previous laptop studies. Based on a thorough review of the literature, the LES scale was comprised of four constructs: academic use, non-academic communication, playing games, and watching movies. The internal reliability, construct validity, convergent validity, and face validity of the LES were assessed.

\section{Addressing methodological concerns}

Four key methodological issues were noted in previous research and addressed in the current study. First, data collection went beyond the typical case study format and focused on a large sample of students. Second, both the reliability and validity of quantitative and qualitative data were provided. Third, all students in this study had equal access to laptop technology, an oversight that was observed in previous papers. Overall, the quality of data collected in this study was sound.

\section{Reliability}

The internal reliability estimates (0.78 to 0.89$)$ for the learning object constructs in the LES were good (Kline, 1999; Nunnally, 1978), as was the inter-rater reliability (99\%) of the categories and ratings used to assess student comments. None of the laptop evaluation studies reviewed for this paper ( e.g. Barak, et al., 2006; Debevec, Shish \& Kashyap, 2006; Kitsantas \& Chow, 2008; Shih \& Mill, 2007) offered reliability statistics, yet it is argued that reliability is a fundamental element of any evaluation tool and should be calculated for future research studies, if the sample size permits.

\section{Validity}

Previous research has not reported validity estimates for scales assessing laptop behaviour during class. Three types of validity were assessed for the LES in this paper: construct, convergent, and face.

\section{- Construct validity}

The principal components analysis revealed four distinct constructs related to the use of laptops during class: academic use, and non-academic - communication, watching movies, and playing games. These constructs are consistent with those proposed by the LES scale and previous research. Furthermore, correlations among the four LES constructs were significant though relatively small. Shared variances among constructs were small enough to support the assumption that each construct measured was distinct.

- Convergent validity

Three variables were used to explore convergent validity: average grade, perception that laptops help academics, and total time that students estimated they were using laptops for non-academic purposes in class. We would predict that academic use of laptops during class would be positively correlated with average grade and student perceptions of laptop usefulness and negatively correlated with student estimates of non-academic use of laptops. These predictions were 
confirmed and indicate a certain level convergent validity for the academic use construct.

One would also predict that the three non-academic constructs (communication, playing games, and watching movies) would be negatively correlated with average grade and student perceptions of laptop usefulness, and positively correlated with student estimates on non-academic use of laptops in class. These predications were supported by the correlation analysis and help establish convergent validity for the non-academic constructs assessed by the LES.

- Content validity

The LES was designed to assess typical behaviours of students while using a laptop in class. For the scale to have content validity, we need to determine the extent to which a measure represents all in-class laptop behaviours displayed by students. Numerous constructs could be assessed but if the behaviours associated with these constructs are rarely observed, the content validity of the scale is compromised. Academic use of laptops, non-academic communication, and playing games were reported frequently enough to support their inclusion in the LES scale. However, only 8 to 11 percent of students watched movies. One might question the necessity of including this construct is the LES scale.

Frequency of student comments about the helpfulness of laptops supported the inclusion of the note taking and general academic activities items in the LES scale. However, student comments provided insight into how the academic use construct might be expanded. First, sharing notes among peers and using posted instructor notes could be added as these behaviours were noted frequently. Second, communicating to other students (e.g., through email or instant messaging) for academic purposes and using course resources might provide more detail and substance to the "general" academic activities item. Third, a new item reflecting student learning (e.g., organisation, increased focus) should probably be added given that almost $30 \%$ of the students commented on these behaviours. Finally, a question about laptops supporting students with special needs during class may be worth adding.

Student comments about unhelpful behaviour were consistent with the inclusion of non-academic communication behaviours, playing games, and watching movies in the LES scale. One item that could be added to the LES scale is a general question about distracting behaviour. This notion of "general distraction" was the most frequent observation made by students, yet it was not directly incorporated in the LES scale. A final item that might be added is surfing the web for non-academic purposes.

In conclusion, the frequency data on laptop behaviour and student comments support the inclusion of the existing LES constructs, although, new items may need to be added to establish content validity.

\section{Summary}

The purpose of this study was to develop and evaluate a scale used to assess in-class use of laptops in higher education. The Laptop Evaluation Scale consisted of four constructs: academic use, non-academic communication, playing games, and watching movies. All scale items showed acceptable internally reliability. A principal components factor analysis demonstrated good construct validity. Correlation among the LES constructs were significant but small enough to support the existence of four 
distinct constructs. All four LES constructs were correlated with average grade, time spent on non-academic activities, and perceptions of laptop helpfulness in class, thereby proving evidence for convergent validity. Finally, content validity was supported by frequencies of laptop behaviours reported as well as student comments. However, student comments indicate that the content of the LES may need to be expanded to include more specific academic and non-academic behaviours.

\section{Implications for education}

A number of higher education institutions have partially or fully integrated laptops into their programs. To date, a scale has not been developed to assess what students are doing with laptops during class. This study was a first attempt to develop a metric to measure in-class laptop behaviour. Reliability and validity estimates indicate that the LES could be used to assess the academic merits of using laptops in class, as well as the challenges that students may be experiencing. Identifying the level of academic activity in laptop based classes is critical to improving the quality of instruction offered. For example, if the LES indicates that a number of students are distracted by laptops, playing games, or watching movies, then it might be time to reflect on how this tool is being used.

In addition, using the LES might be a good start to examining factors that improve the quality of laptop based education. Comparing classes that score high on academic use with those that score high on non-academic use could help to provide important information about designing more effective teaching strategies.

\section{Caveats and future research}

Data from the LES appeared to be reliable and valid. Nonetheless, there are several caveats that should be addressed to guide future research.

First, the sample size, while relatively large, consisted of mostly social science and business students. The LES needs to be tested on a wider variety of subject areas where use of laptops could vary widely. Second, evidence based on student comments indicates that the LES may need to be expanded to include more specific examples of academic and non-academic use. A more comprehensive scale will provide a more accurate reflection of in-class laptop behaviour. Third, while qualitative data were collected in the form of written feedback, it might be prudent to collect focus group data in order to expand upon the possible laptop behaviours that students might be expressing. Fourth, the type of laptop behaviours observed is partially dependent on the "latest" technological trends. Academic and non-academic behaviour may need to be added or subtracted depending on how the technology changes. Finally, it would be a good next step to assess the predictive validity of the LES constructs with respect to student performance in the actual class where the laptop was being used.

\section{References}

Arend, B. D. (2004). New patterns of student engagement. About Campus, 9(3), 30-32.

Barak, M., Lipson, A. \& Lerman, S. (2006). Wireless laptops as means for promoting active learning in large lecture halls. Journal of Research on Technology in Education, 38(3), 245-263.

Barkhuus, L. (2005). Bring your own laptop unless you want to follow the lecture: Alternative communication in the classroom. Proceedings of the 2005 international ACM SIGGROUP conference on Supporting Group Work, 140-143. 
Bhave, M. P. (2002). Classrooms with wi-fi. T.H.E. Journal, 30(14), 17-20. [verified 20 Mar 2010] http: / / thejournal.com/articles / 2002/11/01/ classrooms-with-wifi.aspx

Birrenkott, G., Birtrand, J. A. \& Bolt, B. (2005). Incorporating laptop technologies into an animal sciences curriculum. New Directions for Teaching and Learning, 101, 61-66.

Brown, D. G. (2005). Concluding comments: Laptop learning communities. New Directions for Teaching and Learning, 101, 89-94.

Brown, D. G. \& Petitto, K. R. (2003). The status of ubiquitous computing. Educause Review, 38, 2533. http:/ / net.educause.edu/ir/library/pdf/erm0331.pdf

Caudill, J. (2007). The growth of m-learning and the growth of mobile computing: Parallel developments. International Review of Research in Open and Distance Learning, 8(2), 1-13. http: / / www.irrodl.org/index.php/irrodl/article/view/348/873

Crook, C. \& Barrowcliff, D. (2001). Ubiquitous computing on campus: Patterns of engagement by university students. International Journal of Human-Computer Interaction, 13(2), 245-256.

Debevec, K., Shih, M. \& Kashyap, V. (2006). Learning strategies and performance in a technology integrated classroom. Journal of Research on Technology in Education, 38(3), 293-307.

Demb, A., Erickson, D. \& Hawkins-Wilding, S. (2004). The laptop alternative: Student reactions and strategic implications. Computers $\mathcal{E}$ Education, 43(4), 383-401.

Dickson, G. W. \& Segars, A. (1999). Redefining the high-technology classroom. Journal of Education for Business, 74(3), 152.

Finn, S. \& Inman, J. G. (2004). Digital unity and digital divide: Surveying alumni to study effects of a campus laptop initiative. Journal of Research on Technology in Education, 36(3), 297-317.

Fried, C. B. (2008). In-class laptop use and its effects on student learning. Computers $\mathcal{E}$ Education, 50(3), 906-914.

Gay, G., Stefanone, M., Grace-Martin, M. \& Hembrooke, H. (2001). The effects of wireless computing in collaborative learning environments. International Journal of Human-Computer Interaction, 13(2), 257-276.

Grace-Martin, M. \& Gay, G. (2001). Web browsing, mobile computing and academic performance. Educational Technology and Society, 4(3), 95-107. http: / / www.ifets.info/journals/4_3/grace_martin.html

Granberg, E. \& Witte, J. (2005). Teaching with laptops for the first time: Lessons from a social science classroom. New Directions for Teaching and Learning, 101, 51-59.

Guadagnoli, E. \& Velicer, W. (1988). Relation of sample size to the stability of component patters. Psychological Bulletin, 103, 265-275.

Hembrooke, H. \& Gay, G. (2003). The laptop and the lecture: The effects of multitasking in learning environments. Journal of Computing in Higher Education, 15(1), 46-64.

Hyden, P. (2005). Teaching statistics by taking advantage of the laptop's ubiquity. New Directions for Teaching and Learning, 101, 37-42.

Kitsantas, A. \& Chow, A. (2007). College students' perceived threat and preference for seeking help in traditional, distributed, and distance learning environments. Computers $\mathcal{E}$ Education, 48(3), 383-395.

Kline, P. (1999). The handbook of psychological testing (2nd edition). London: Routledge.

Lauricella, S. \& Kay, R. H. (2009). Appendix A - The Laptop Effectiveness Scale. http: / / faculty.uoit.ca/kay/papers/les/AppendixA_LES.pdf

McVay, G. J., Snyder, K. D. \& Graetz, K. A. (2005). Evolution of a laptop university: A case study. British Journal of Educational Technology, 36(3), 513-524.

Mitra, A. \& Steffensmeier, T. (2000). Changes in student attitudes and student computer use in a computer-enriched environment. Journal of Research on Computing in Education, 32(3), 417. 
Motiwalla, L. F. (2007). Mobile learning: A framework and evaluation. Computers $\mathcal{E}$ Education, 49(3), 581-596.

Nunnally, J. C. (1978). Psychometric theory. New York: McGraw-Hill.

Ohland, M. W. \& Stephan, E. A. (2005). Using laptops in engineering courses for real-time data collection and analysis. New Directions for Teaching and Learning, 101, 67-79.

Pargas, R. P. \& Weaver, K. A. (2005). Laptops in computer science: Creating the "learning studio". New Directions for Teaching and Learning, 101, 43-51.

Partee, M. H. (1996). Using e-mail, web sites, and newsgroups to enhance traditional instruction. T.H.E. Journal, 23(11), 79-82. http: / / thejournal.com/Articles/1996/06/01/Using-EMail-WebSites--Newsgroups-to-Enhance-Traditional-Classroom-Instruction.aspx

Rapp, D. N. The value of attention aware systems in educational settings. Computers in Human Behavior, 22(4), 603-614.

Reynolds, R. Making IM work for education. [viewed 29 Apr 2009, not found 20 Mar 2010] http: / / www.xplanazine.com/2003/04/ making-im-work-for-education-part-1

Shih, Y. E. \& Mills, D. (2007). Setting the new standard with mobile computing in online learning. International Review of Research in Open and Distance Learning, 8(2). http: / / www.irrodl.org/index.php/irrodl/article/view/361/872

Siegle, D. \& Foster, T. (2001). Laptop computers and multimedia and presentation software: Their effects on student achievement in anatomy and physiology. Journal of Research on Technology in Education, 34(1), 29-37.

Stephens, B. (2005). Laptops in psychology: Conducting flexible in-class research and writing laboratories. New Directions for Teaching and Learning, 101, 15-26.

Stevens, J. P. (1992). Applied multivariate statistics for the social science applications (2nd edition). Hillsdale, NJ: Erlbaum.

Trimmel, M., \& Bachmann, J. (2004). Cognitive, social, motivational and health aspects of students in laptop classrooms. Journal of Computer Assisted Learning, 20(2), 151-158.

Weaver, B. E. (2005). Laptops in the humanities: Classroom walls come tumbling down. New Directions for Teaching and Learning, 101, 81-88.

Weaver, B. E. \& Nilson, L. B. (2005). Laptops in class: What are they good for? What can you do with them? New Directions for Teaching and Learning, 101, 3-13.

Wurst, C., Smarkola, C. \& Gaffney, M. A. (2008). Ubiquitous laptop usage in higher education: Effects on student achievement, student satisfaction, and constructivist measures in honors and traditional classrooms. Computers $\mathcal{E}$ Education, 51(4), 1766-1783.

Young, J. R. (2006). The fight for classroom attention: Professor vs. laptop. Chronicle of Higher Education, 52(39), A27-A29.

Zucker, A. (2004). Developing a research agenda for ubiquitous computing in schools. Journal of Educational Computing Research, 30(4), 371-386.

Dr Sharon Lauricella, Assistant Professor

Faculty of Criminology, Justice and Policy Studies

University of Ontario Institute of Technology.

Email: Sharon.Lauricella@uoit.ca

Web: http:/ / criminologyandjustice.uoit.ca/EN/main/ faculty_staff/lauricella.php

Dr Robin Kay (corresponding author), Associate Professor

Faculty of Education, University of Ontario Institute of Technology

11 Simcoe St N, Oshawa ON L1H 7L7, Canada

Email: Robin.Kay@uoit.ca Web: http: / / faculty.uoit.ca/kay/home / 